\title{
Arte y Trabajo Social: un programa de intervención para transformar la visión de la sociedad para la inclusión de personas con demencia temprana y Alzheimer ${ }^{1}$
}

\author{
Art and Social Work: an intervention programme for transforming society's \\ vision to include people with early-onset dementia and Alzheimer's
}

\author{
Lorena LÓPEZ MÉNDEZ \\ Universidad Complutense de Madrid, España \\ lorena.lopez@ucm.es
}

Recibido: $16 / 05 / 2015$

Revisado: 01/06/2015

Aceptado: 15/09/2015

Disponible on line: 20/01/2016

\begin{abstract}
Resumen
El presente artículo expone un programa que se enmarca en el campo del Arte y la Educación como herramientas en el Trabajo Social para la inclusión de personas diagnosticadas de demencia temprana y Alzheimer, para erradicar estigmas y mitos asociados a la enfermedad.

El programa se inscribe en el Proyecto ARS (Arte y Salud Alzheimer) de la Junta de Castilla y León y del Fondo Social Europeo. Se muestran una serie de actividades artístico-educativas evaluadas para que puedan desarrollarlas las personas con la enfermedad de Alzheimer en fase incipiente y empleadas por cuidadores y familiares para trabajar con este perfil de personas, con el objetivo de mejorar su bienestar, autoestima y calidad de vida.
\end{abstract}

Palabras clave: arte, Trabajo Social, demencia temprana, empoderamiento, actividades artístico-educativas.

\begin{abstract}
This paper presents a program centred on arts and education as tools in social work for the inclusion of people with earlyonset dementia and Alzheimer's. The objective of the programme is to eradicate the stigma and myths associated with the disease.

The program is part of the Junta de Castilla y León and the European Social Fund's ARS Project (Arte y Salud Alzheimer; Alzheimer's Art \& Health). The programme presents a series of evaluated artistic and educational activities that can be undertaken by people in the early stages of Alzheimer's disease and that can also be used by caregivers and family when working with this group of people, with the aim of improving their wellbeing, self-esteem and quality of life.
\end{abstract}

Keywords: art, Social Work, early-onset dementia, empowerment, artistic-educational activities.

Referencia normalizada: López Méndez, L. (2016): «Arte y Trabajo Social: programa de intervención para transformar la visión de la sociedad para la inclusión de personas con demencia temprana y Alzheimer». Cuadernos de Trabajo Social, 29(1): 51-61.

Sumario: Introducción. 1. Arte y Trabajo Social: vínculos y relaciones. 2. El proyecto AR.S: arte y Salud Alzheimer. 3. Metodología. 4. Marco práctico: actividades artístico-educativas y herramientas para la inclusión. 5. Resultados.

6. Conclusiones. 7. Referencias bibliográficas.

\section{Introducción}

Actualmente las enfermedades neurodegenerativas en la tercera edad, concretamente la enfermedad de Alzheimer y otras demencias, se presentan como uno de los grandes retos de la humanidad del siglo XXI, dado el crecimiento exponencial de las personas con esta afección, hecho que ha provocado que la comunidad científica se sensibilice con las problemáticas asociadas a la vejez, requiriendo que su investigación se aborde desde perspectivas multidisciplinares que permitan avanzar tanto en los tratamientos

${ }^{1}$ El artículo se inserta en el Proyecto AR.S (Arte y Salud Alzheimer), al amparo de la Beca Predoctoral PIRTU (Orden EDU/1204/2010, de 26 de agosto) concedida a su autora y financiada por la Junta de Castilla y León y el Fondo Social Europeo. 
farmacológicos como no farmacológicos o terapéuticos, y en los sistemas de cuidado de estas personas que potencien al máximo sus capacidades y retrasen, en la medida de lo posible, su proceso de incapacitación.

En el presente artículo, el Trabajo Social se expone como vehículo y guía en (y para) su convivencia con el arte en los procesos de creación artística, pudiendo aportar nuevas perspectivas para la mejora en la atención de personas con demencia temprana, y para su participación y disfrute de la cultura, sin ánimo de maquillar la cruda realidad social en que viven estas personas y su entorno; sino más bien con ánimo de reconstruir y descubrir nuevas formas de trabajo, desde una perspectiva multidisciplinar y transversal, donde la experiencia vital (historia de vida), las sensaciones y emociones sean los pilares más importantes para la intervención social.

Entendemos la intervención social como suma y unión de los parámetros del Trabajo Social y arte, como nuevas posibilidades de diálogo entre ambas disciplinas, con un fin de transformar la visión de la sociedad, mostrando las capacidades y potenciales que todavía pueden permanecer en personas con demencia temprana en fases leves e iniciales, porque se precisa una investigación participativa. Tal y como sostiene Bud L. Hall (1983, pp. 3-15, citado en Molina y Romero, 2004, pp. 140-141), el trabajo creativo e intelectual de cientos de personas ha enriquecido y puede seguir enriqueciendo el proceso creativo de la teoría y la práctica de la investigación participativa que surge de problemas cuya solución urge y cuyo propósito es la movilización de las personas para la creación colectiva del conocimiento sobre sí mismas y su propia realidad.

La investigación participativa, en campo del Arte, se entiende como un arte contextual y participativo. Paul Ardenne (2006, p. 122) postula al respecto que todo contacto con una obra de arte es por sí misma participación; pero el arte participativo, va más allá y busca, de manera abierta y a menudo espectacular, la implicación del espectador. Desde comienzos del siglo XX numerosos artistas abandonaron las prácticas del arte tradicional para sumergirse en formas artísticas inéditas, en las que el arte se muestra como un arte comprometido, un arte de intervención de carácter activista, y en el que el artista se convierte en un actor social implicado.
1. Arte y Trabajo Social: vínculos y relaciones

El Trabajo Social en España, como sostienen García y Melián (1993), para determinadas personas sigue vinculado a los conceptos de beneficencia y asistencia, pero en los últimos años se considera como transdisciplinar, es decir se está enmarcando en la convergencia teórica y metodológica de diversas y variadas disciplinas. En este punto, el arte puede tener especial importancia para la intervención con personas en un contexto de vulnerabilidad, ofreciéndoles la posibilidad de empoderarlas a través de las artes plásticas y visuales, compartiendo procesos creativos.

El arte en Trabajo Social puede ser una herramienta apta para utilizarse con las personas mayores con capacidades diferentes y, concretamente, con personas afectadas por demencia temprana y Alzheimer. A través de la creatividad tenemos la oportunidad de compartir la cultura de manera multidisciplinar y transversal, así como contribuir a un envejecimiento activo de las personas de este perfil. Asimismo podemos explicar realidades que la sociedad no conoce mediante una experiencia vital y cercana de procesos creativos, porque es la difusión el modo como podemos transmitir el conocimiento. Transmitir esta realidad, sensibilizando y dando voz a las personas aquejadas por la enfermedad de Alzheimer en las primeras fases y a sus familiares cuidadores, ofreciéndoles la posibilidad de explicar su realidad.

Existen estudios que sostienen que los talleres de artes creativas pueden considerarse actividades significativas en la estimulación cognitiva, funcional y ejecutiva, y promueve un envejecimiento activo (Calzado, Ruiz y Espada, 2013), pues ofrecen a los usuarios que las practican, una oportunidad para la participación, el ocio, la comunicación y la socialización; repercutiendo así en retrasar el declive de sus funciones cognitivas, mejorando de la calidad de vida y la autoestima del/la participante (Marshall \& Hutchinson, 2001; Stuckey \& Nobel, 2010; Palmiero. Di Giacomo \& Passafiume, 2012; Eekelaar, Camic \& Springham, 2012; Camic \& Chatterjee, 2013; Camic, Tischler \& Pearman, 2014; Chancellor, Duncan \& Chatterjee, 2014; Young, Camic \& Tischler, 2015).

\section{El proyecto AR.S: Arte y Salud Alzheimer} En 2010 se puso en marcha el proyecto AR.S (Arte y Salud Alzheimer) bajo la dirección de Ana $\mathrm{M}^{\mathrm{a}}$ Ullán de la Fuente y Manuel Hernández Belver. Pretende diseñar e implementar progra- 
mas de actividades artísticas para personas con Alzheimer y otras demencias, abierto a la participación de cuidadores y familiares, intentando dar respuesta a las necesidades del colectivo citado.

En el proyecto participan el Departamento de Psicología Social y Antropología de la Universidad de Salamanca y el Departamento de Didáctica de la Expresión Plástica de la Facultad de Bellas Artes de la Universidad Complutense de Madrid, junto al Museo Pedagógico de Arte Infantil y Adolescente (MUPAI).

El proyecto AR.S: Arte y Salud apuesta por el empleo del arte como herramienta para ayudar a las personas con Alzheimer y otras demencias, así como al personal sociosanitario y, por ende, a los/as trabajadores sociales para facilitarles la comunicación e inclusión en su entorno (familiares, amigos, personal del centro o residencia, etc.) a la par que se estimulan sus capacidades sensoriales y cognitivas, reduciendo el estigma social que existe alrededor del concepto Alzheimer (López, 2014).

Conscientes de que son pocas las oportunidades de accesibilidad de estas personas a la vida cultural de la comunidad, no debería justificarse porque la enfermedad les impida relacionarse con el arte, porque el arte - como decía John Dewey (1949) - es experiencia, una experiencia que para el conocimiento hay que aprender el objeto en su relación con el sujeto y con el medio.

En la actualidad, existen escasas investigaciones de las actividades artísticas con personas con demencia, sin trayectorias artísticas previas a su enfermedad, pero las pocas experiencias justificadas coinciden en que la demencia en sí no supone un obstáculo para consumos culturales artísticos, como visitas a galerías de arte o museos (MacPherson, Bird, Anderson, Davis \& Bliar, 2009; Ziesel, 2009; Ullán, 2011).

\section{Metodología}

El programa se implementó en colaboración con el Centro de Referencia Estatal de Atención a personas con la enfermedad de Alzheimer $\mathrm{y}$ otras demencias de Salamanca (CRE) (http://www.crealzheimer.es/crealzheimer_01/in dex.htm). Situado en Salamanca, se configura como un centro sociosanitario especializado y avanzado en investigación, análisis, conocimiento, evaluación y formación sobre Alzheimer y otras demencias, y en atención e intervención con las personas afectadas y sus familias.
En el programa se consideraron elegibles todos los usuarios del centro (CRE) en fase moderada, (GDS 4 a 5 en la escala de Reisberg) y en MMSE presentaban una valoración entre $12 \mathrm{y}$ 27 puntos $(\mathrm{M}=20, \mathrm{SD}=3,6)$. A todos ellos $(\mathrm{N}=17)$ se les ofreció la posibilidad de incorporarse al programa. Finalmente participaron de manera continuada 16 usuarios, 8 usuarios del centro de día ( 7 mujeres y 1 hombre) y 8 usuarios ( 7 mujeres y 1 hombre) de unidades de convivencia, seleccionadas por su interés por el arte y sus procesos técnicos (Imagen 1).

La metodología implementada para el análisis y la sistematización de las sesiones fue de carácter cualitativo, concretamente se llevó a cabo una observación participante, así como entrevistas no estructuradas a las auxiliares-cuidadoras y al personal socio-sanitario. Uno de los objetivos era obtener una perspectiva de terceros sobre cómo estaba diseñada la intervención. Todos los datos se registraron como notas de campo o de capturaron con una cámara fotográfica digital, grabadora y se transcribieron posteriormente. Respecto al análisis de datos se aplicó el programa de análisis de datos atlas.ti (versión 7) que nos permitió establecer la triangulación de la información recogida de los datos.

Asimismo para la metodología de intervención de cada sesión, nos centramos en los modelos de comunicación y atención integral centrados en la persona (Brooker, 2013), desarrollados ampliamente por Kitwood (1997), quien describió el modelo como un intento de obtener el punto de vista de la persona con demencia, empleando la combinación entre técnica observacional y empatía. Al respecto, Yanguas (2005) considera que la atención de este perfil de enfer-

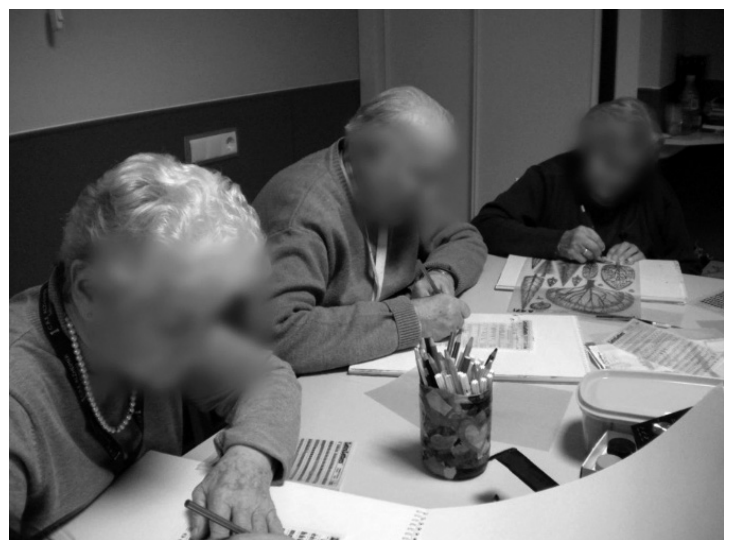

Imagen 1. Proceso Taller Alfabeto Visual. 
mo debe afrontarse desde dos ejes: la prevención o rehabilitación de todas sus capacidades y la integración o intervención y participación. En dicho modelo se insiste en la importancia de que se mantenga la identidad de la persona con demencia, pues en numerosas ocasiones algunas de sus alteraciones conductuales son la respuesta a su malestar por falta de comprensión a sus necesidades individuales.

Del mismo modo nos apoyamos en el método de validación de Naomi Feil (1980), quien considera que validar es reconocer los sentimientos de una persona, es decir, indicar que sus sentimientos son ciertos. Por lo tanto, utilizamos la empatía para sintonizar con la realidad de la persona con demencia, aportándole seguridad, fuerza y capacidad de valía, siendo esta una manera de devolverle su dignidad y sentimiento de capacidad, transmitiendo una imagen positiva de ella misma (Ullán, 2011).

Por último, el programa se sostuvo en la unión de los métodos anteriores como modelo y con la finalidad en la atención socioeducativa que nos plantea Molina y Romero, (2004, p.158) en el Esquema $n^{\circ} 56$, adaptándolo a un método de atención socieducativa a través del arte y la participación (Gráfico 1).

\section{Marco práctico: actividades artístico-edu- cativas y herramientas para la inclusión}

El programa de educación artística se configuró en 28 sesiones, durante 5 meses a razón de una se- sión semanal de 1 hora y 30 minutos en formato grupal ( 2 grupos de 8 usuarios máximo). La intervención se realizó entre las 15:00 h y las 19:00 h., en un espacio designado específicamente para la actividad y aislado de las unidades de convivencia y el centro de día. Las sesiones se llevaron a cabo con la presencia de una experta en Educación artística, una educadora social, una auxiliar de clínica y una trabajadora social, que realizaba una vista previa a la sesión en el taller y otra posterior.

En el diseño del programa se tomaron una serie de criterios básicos para el desarrollo del programa (Ullán et al., 2012) y los talleres piloto (Cuadro 1), diseñados e implementados fueron concretamente nueve, llevado a cabo en tres fases:

\subsection{Fase de análisis o APRECIACIÓN}

Presentación de contenido audiovisual con imágenes de artistas que se tomaron como referencia, por medio del uso y la introducción de las tecnologías de la información y la comunicación (TIC). Estas imágenes nos permitieron generar un archivo físico y digital con ellas sobre una temática concreta, para abrir el diálogo y la conversación con los participantes, siempre estableciendo relaciones y vínculos con su contenido vital e historia biográfica. Tratamos del concepto de «pensar en imágenes o con imágenes» (Aidelman y de Lucas, 2010) que sirvió de apoyo para llevar a cabo, durante el transcurso de esta primera fase, la técnica de intervención reminiscencia; técnica que nos permite recordar, elabo-

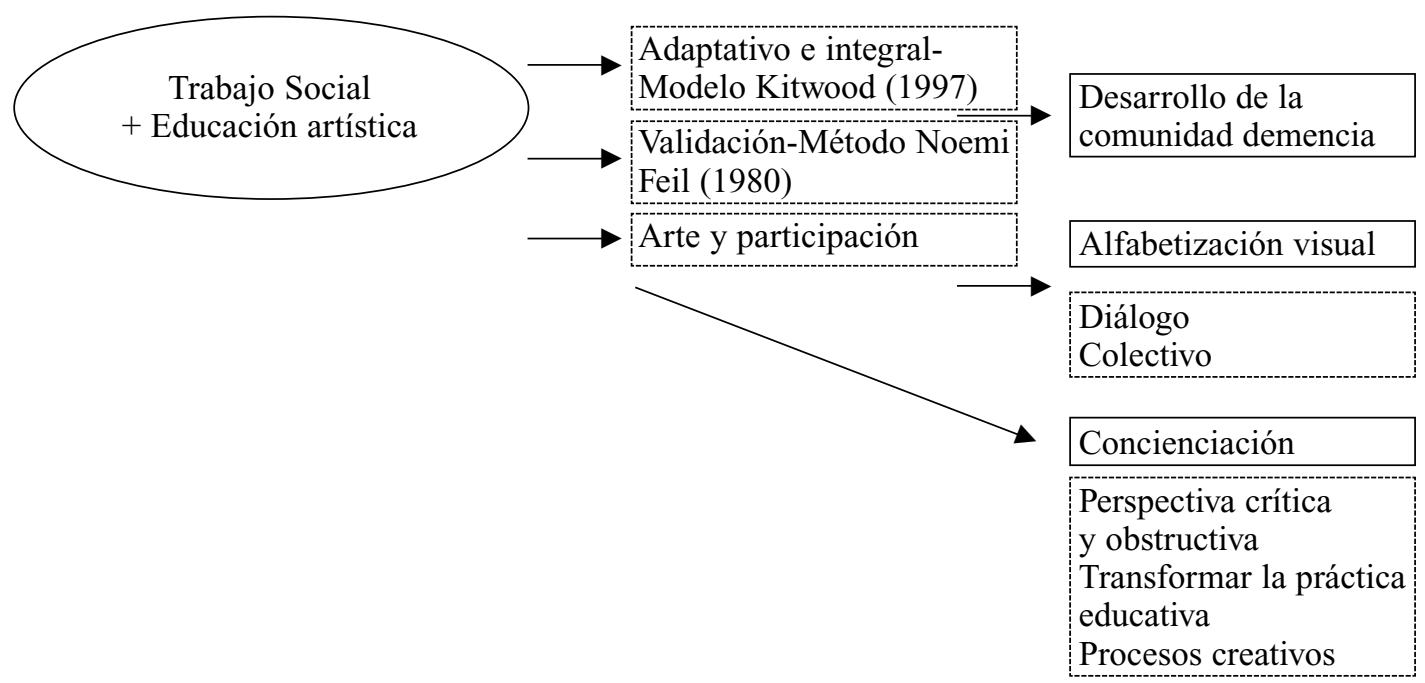

Gráfico 1. Método con finalidad socioeducativa y artística.

Fuente: Adaptación del Esquema n. ${ }^{\circ}$ 56, Molina y Romero, 2004, p. 158. 


\begin{tabular}{|c|c|c|c|}
\hline $\begin{array}{l}\text { Taller } \\
\text { (Título) }\end{array}$ & Resumen & Estimulación cognitiva & Técnica/soporte \\
\hline $\begin{array}{l}\text { 1. Mapas de me- } \\
\text { moria un mun- } \\
\text { do de color }\end{array}$ & $\begin{array}{l}\text { El objetivo de este proyecto es acer- } \\
\text { car a los participantes al uso del co- } \\
\text { lor, familiarizándoles no sólo con } \\
\text { su teoría sino también con las emo- } \\
\text { ciones que producen, llegando a re- } \\
\text { flexionar sobre la creación de nue- } \\
\text { vas identidades a través de su uso. }\end{array}$ & $\begin{array}{l}\text { Memoria a largo plazo y } \\
\text { reminiscencia } \\
\text { - Ejercicios relaciona- } \\
\text { dos con datos personales, } \\
\text { memoria bibliográfica, } \\
\text { por medio del color. } \\
\text { - Rememoración de } \\
\text { acontecimientos históri- } \\
\text { cos o de personajes cono- } \\
\text { cidos. }\end{array}$ & $\begin{array}{l}\text { Acuarela líqui- } \\
\text { da/soporte papel. }\end{array}$ \\
\hline $\begin{array}{l}\text { 2. Alfabeto vi- } \\
\text { sual-poesía vi- } \\
\text { sual con cali- } \\
\text { gramas }\end{array}$ & $\begin{array}{l}\text { El principal sistema gráfico de re- } \\
\text { presentación humano es la escritu- } \\
\text { ra, y por medio de signos trazados } \\
\text { sobre un soporte logramos comuni- } \\
\text { carnos y transmitir información, es- } \\
\text { te es el objetivo de este taller, lograr } \\
\text { que los participantes se comuni- } \\
\text { quen mediante la representación de } \\
\text { poesías visuales(caligramas), refra- } \\
\text { nes o dichos populares; ofreciéndo- } \\
\text { les la posibilidad de recordar y re- } \\
\text { flexionar sobre los sistemas de } \\
\text { comunicación y transmisión de } \\
\text { mensajes, a la vez que nos muestran } \\
\text { su sabiduría popular basada en su } \\
\text { experiencia y observación. }\end{array}$ & $\begin{array}{l}\text { Lenguaje-Afasia } \\
\text { Errores semánticos y po- } \\
\text { co a poco se instaura ano- } \\
\text { mia semántica y visual. } \\
\text { - Se altera la sintaxis fi- } \\
\text { nalmente. }\end{array}$ & $\begin{array}{l}\text { Letrasers y lápiz. } \\
\text { Soporte papel. }\end{array}$ \\
\hline $\begin{array}{l}\text { 3. Mirada del } \\
\text { entorno. Foto- } \\
\text { grafia digital pa- } \\
\text { ra explorar el } \\
\text { contexto }\end{array}$ & $\begin{array}{l}\text { A partir del empleo de la fotografía } \\
\text { digital como herramienta, se des- } \\
\text { arrolla el proyecto, con el objetivo } \\
\text { de que los participantes entiendan } \\
\text { el arte como medio para reflexionar } \\
\text { sobre los espacios en los que habi- } \\
\text { tan, cómo están diseñados. De- } \\
\text { sarrollan sus propias fotografías. }\end{array}$ & $\begin{array}{l}\text { Orientación } \\
\text { - Estimular y estructu- } \\
\text { rar la información sobre } \\
\text { sí mismos y su entorno en } \\
\text { el Centro o Asociación. } \\
\text { - Proporcionar infor- } \\
\text { mación básica-espacio y } \\
\text { tiempo. } \\
\text { - Mejorar conductas so- } \\
\text { ciales entre participantes, } \\
\text { personal sociosanitario, } \\
\text { familiares-cuidadores. }\end{array}$ & $\begin{array}{l}\text { Fotografía digi- } \\
\text { tal/impresiones } \\
\text { digitales reali- } \\
\text { zadas por los } \\
\text { participantes. } \\
\text { Acuarela líqui- } \\
\text { da. } \\
\text { Creación de un } \\
\text { archivo del lu- } \\
\text { gar. }\end{array}$ \\
\hline $\begin{array}{l}\text { 4. Paisajes. Jar- } \\
\text { dines impresio- } \\
\text { nistas }\end{array}$ & $\begin{array}{l}\text { Desarrollamos este proyecto partien- } \\
\text { do del concepto de jardín, como es- } \\
\text { pacio público donde se cultivan dife- } \\
\text { rentes especies vegetales y que, en } \\
\text { ocasiones, viene acompañado de } \\
\text { elementos ornamentales como fuen- } \\
\text { tes o esculturas. } \\
\text { Su objetivo es hacer reflexionar so- } \\
\text { bre cómo transformar esos jardines } \\
\text { en espacios aún más saludables y } \\
\text { ergonómicos para personas mayo- } \\
\text { res. Los participantes diseñaran su } \\
\text { prototipo de jardín ideal. }\end{array}$ & $\begin{array}{l}\text { Atención } \\
\text { - Se deteriora en todas } \\
\text { sus variantes-atención: } \\
\text { sostenida-vigilada, selec- } \\
\text { tiva, dividida. } \\
\text { - Dificultades para con- } \\
\text { centrarse y seguir conver- } \\
\text { saciones, lecturas, pelícu- } \\
\text { las... } \\
\text { - Dificultad para reali- } \\
\text { zar tareas simples como } \\
\text { cortar y pegar. }\end{array}$ & $\begin{array}{l}\text { Decollage/acua- } \\
\text { rela líquida so- } \\
\text { bre papel de } \\
\text { acuarela. }\end{array}$ \\
\hline
\end{tabular}




\begin{tabular}{|c|c|c|c|}
\hline $\begin{array}{l}\text { Taller } \\
\text { (Título) }\end{array}$ & Resumen & Estimulación cognitiva & Técnica/soporte \\
\hline $\begin{array}{l}\text { 5. Huellas de la } \\
\text { memoria }\end{array}$ & $\begin{array}{l}\text { El ser humano a lo largo de la his- } \\
\text { toria ha dejado señales, impresiones } \\
\text { y rastros de sus vivencias, estás nos } \\
\text { sirven para desarrollar este proyec- } \\
\text { to, con el objetivo de reflexionar so- } \\
\text { bre el concepto de huella, como im- } \\
\text { pronta del propio cuerpo. En este } \\
\text { proyecto emplearemos el grabado } \\
\text { (collagraph) como herramienta pa- } \\
\text { ra comunicar emociones, senti- } \\
\text { mientos. }\end{array}$ & $\begin{array}{l}\text { Gnosias:visual } \\
\text { - Figuras superpuestas. } \\
\text { - Reconocimiento de } \\
\text { siluetas. } \\
\text { - Reconocimiento de } \\
\text { un todo a partir de sus } \\
\text { partes. } \\
\text { - Figuras enmascaradas. }\end{array}$ & $\begin{array}{l}\text { Grabado-colla- } \\
\text { graph. } \\
\text { Soporte cartón. }\end{array}$ \\
\hline $\begin{array}{l}\text { 6. Un gesto una } \\
\text { historia }\end{array}$ & $\begin{array}{l}\text { Conscientes de que el trabajo es una } \\
\text { actividad por la que el hombre ob- } \\
\text { tiene su medio de subsistencia, con } \\
\text { el objetivo de recibir algo a cambio. } \\
\text { Consideramos ese concepto para } \\
\text { dialogar sobre el oficio que desem- } \\
\text { peñaron los participantes y analizar } \\
\text { cómo ha ido cambiando a lo largo } \\
\text { de la historia, como también ha } \\
\text { cambiado el concepto de Artista. } \\
\text { Emplearemos la pintura como he- } \\
\text { rramienta para representar nuestro } \\
\text { proyecto. }\end{array}$ & $\begin{array}{l}\text { Funciones ejecutivas } \\
\text { - Actividad mental im- } \\
\text { plicada en la planifica- } \\
\text { ción, iniciación y regula- } \\
\text { ción del comportamiento: } \\
\text { secuenciación, planifica- } \\
\text { ción, abstracción, razona- } \\
\text { miento. } \\
\text { - Inhibición, juicio crí- } \\
\text { tico, toma de decisiones. } \\
\text { - Atender varias cosas } \\
\text { al mismo tiempo. }\end{array}$ & $\begin{array}{l}\text { Pintura/soporte } \\
\text { tabla. }\end{array}$ \\
\hline $\begin{array}{l}\text { 7. Exposición } \\
\text { virtual-nunca es } \\
\text { tarde. Relacio- } \\
\text { nes y vinculos }\end{array}$ & $\begin{array}{l}\text { En este proyecto se pretendió esta- } \\
\text { blecer relaciones y vínculos entre } \\
\text { las obras realizadas por los partici- } \\
\text { pantes con respecto a obras de ar- } \\
\text { tistas legitimados, con la intención } \\
\text { de revalorizar el valor artístico de } \\
\text { las obras de los participantes, ha- } \\
\text { ciéndoles reflexionar sobre sus po- } \\
\text { sibles capacidades, que todavía } \\
\text { perduran a pesar de la enferme- } \\
\text { dad. }\end{array}$ & $\begin{array}{l}\text { Memoria a largo plazo y } \\
\text { reminiscencia. } \\
\text { - Ejercicios relaciona- } \\
\text { dos con datos personales, } \\
\text { memoria bibliográfica, } \\
\text { por medio de las obras re- } \\
\text { alizadas por los partici- } \\
\text { pantes. } \\
\text { - Rememoración de } \\
\text { acontecimientos vividos } \\
\text { por los participantes } \\
\text { durante los procesos lle- } \\
\text { vados a cabo en cada ta- } \\
\text { ller. }\end{array}$ & $\begin{array}{l}\text { Imágenes digi- } \\
\text { talizadas de las } \\
\text { obras de los } \\
\text { participantes } \\
\text { vinculadas a } \\
\text { imágenes de } \\
\text { obras de artistas } \\
\text { legitimados por } \\
\text { su razonable pa- } \\
\text { recido estetico. }\end{array}$ \\
\hline $\begin{array}{l}\text { 8. Trazos. Sen- } \\
\text { cillez cotidiana }\end{array}$ & $\begin{array}{l}\text { El objetivo de este proyecto es } \\
\text { construir una serie de piezas cuya } \\
\text { herramienta predominante para } \\
\text { crearla es la técnica del SUMI-E y } \\
\text { como temática la naturaleza que } \\
\text { nos rodea (plantas silvestres), co- } \\
\text { mo esencia y propiedad caracterís- } \\
\text { tica de cada ser. Por lo tanto, invita- } \\
\text { mos al participante a reflexionar } \\
\text { sobre la naturaleza y cómo esta in- } \\
\text { fluye en nuestro entorno y vida co- } \\
\text { tidiana. }\end{array}$ & $\begin{array}{l}\text { Atención } \\
\text { - Se deteriora en todas } \\
\text { sus variantes-atención: } \\
\text { sostenida-vigilada, selec- } \\
\text { tiva, dividida. } \\
\text { - Dificultades para con- } \\
\text { centrarse y seguir conver- } \\
\text { saciones, lecturas, pelícu- } \\
\text { las... } \\
\text { - Dificultad para reali- } \\
\text { zar tareas simples. }\end{array}$ & $\begin{array}{l}\text { Sumi-e- tinta } \\
\text { china/Soporte- } \\
\text { Papel de acua- } \\
\text { rela. } \\
\text { Papel estraza. }\end{array}$ \\
\hline
\end{tabular}




\begin{tabular}{|c|c|c|c|}
\hline $\begin{array}{l}\text { Taller } \\
\text { (Título) }\end{array}$ & Resumen & Estimulación cognitiva & Técnica/soporte \\
\hline $\begin{array}{l}\text { 9. Risas y hu- } \\
\text { mor }\end{array}$ & $\begin{array}{l}\text { El objetivo de este proyecto es in- } \\
\text { centivar al participante a tener una } \\
\text { visión positiva y humorística de los } \\
\text { errores que cometemos en nuestra } \\
\text { vida diaria y de las anécdotas que } \\
\text { nos ocurren. } \\
\text { Recurrimos a monólogos de humor } \\
\text { de Gila, Eugenio y Martes y Trece } \\
\text { entre otros. Asimismo utilizamos } \\
\text { fotocopias de chistes cortos que } \\
\text { convertimos en puzzles y que él y la } \\
\text { participante debía reconstruir e in- } \\
\text { tervenir si lo deseaba oportuno. }\end{array}$ & $\begin{array}{l}\text { Atención } \\
\text { - Se deteriora en todas } \\
\text { sus variantes-atención: } \\
\text { sostenida-vigilada, selec- } \\
\text { tiva, dividida. } \\
\text { - Dificultades para con- } \\
\text { centrarse y seguir conver- } \\
\text { saciones, lecturas, pelícu- } \\
\text { las... } \\
\text { - Dificultad para reali- } \\
\text { zar tareas simples. }\end{array}$ & $\begin{array}{l}\text { Chistes. } \\
\text { Soporte-papel. } \\
\text { Pegamento y ti- } \\
\text { jeras. } \\
\text { Dibujo. }\end{array}$ \\
\hline
\end{tabular}

Cuadro 1. Talleres realizados en el Programa de Educación Artística en el Centro CRE de Alzheimer.

rar cognitiva y afectivamente pensando o relatando hechos, actos o vivencias del pasado, a partir de acontecimientos o experiencias remotas. Permitiéndonos reconstruir la cartografía de vida de los participantes, ese álbum que guardamos en nuestra memoria y que se desmorona por el trascurso y evolución de la enfermedad.

\subsection{Fase de PRODUCCIÓN}

Realización de obra personal por los participantes. Recurrimos al empleo de diferentes técnicas del campo del Arte (dibujo, pintura, escultura y fotografía), en cada sesión se enseñaba una en concreto, que tuviese relación directa con lo expuesto en la fase de apreciación de imágenes. Estas técnicas sirvieron como herramientas para enseñar un proceso para que los participantes fuesen capaces de realizarlo paso a paso, generando una rutina en la intervención. Una vez llevada a cabo la técnica en varias ocasiones, el participante lograba ejecutarla de manera casi independiente. Asimismo apuntábamos en una pizarra los pasos a seguir de manera sintética para facilitar su recuerdo (Imágenes 2 y 3 ).

\subsection{Fase puesta en COMÚN}

Esta se subdivide en dos apartados:

4.3.1. Debate previo a la realización de la fase de producción.

\subsubsection{Diálogo de los resultados obtenidos.}

En esta fase cada participante mostraba el resultado de su obra y respondía a las preguntas que la

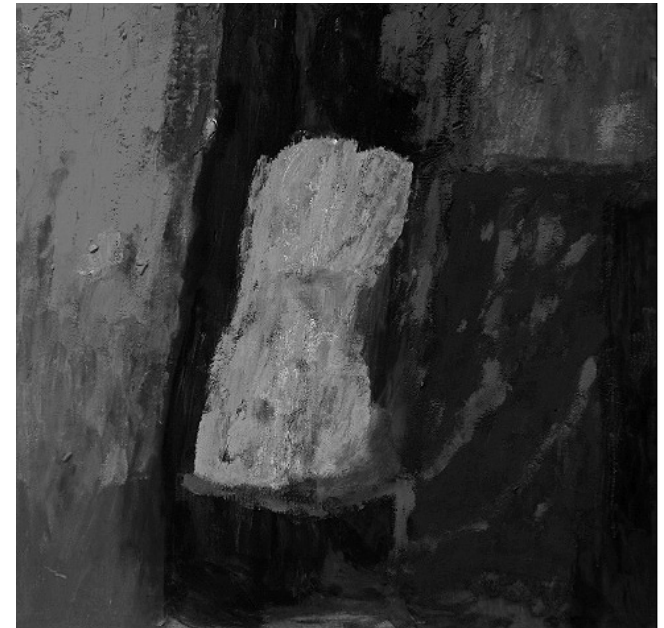

Imagen 2. Participante S. Mujer de espaldas. Acrílico sobre lienzo, $50 \times 50 \mathrm{~cm}$. Taller-Un gesto una historia.

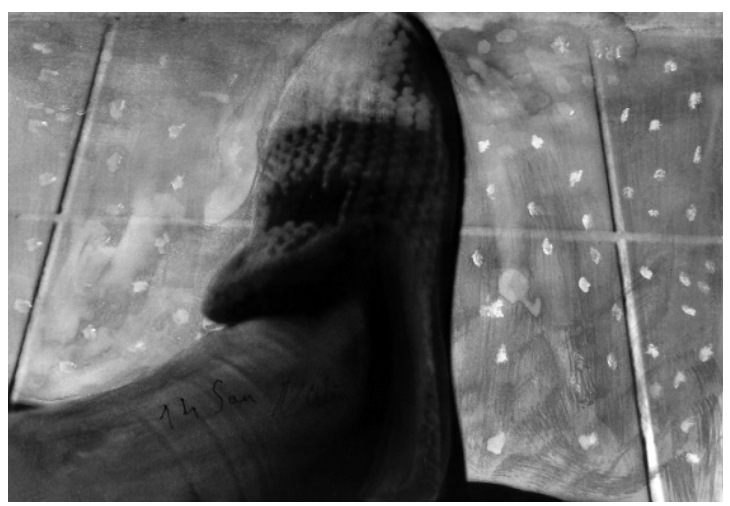

Imagen 3. Participante T. Mi Zapatilla. Fotografía en $\mathrm{B} / \mathrm{N}$ intervenida con acuarela. Taller-Miranda del Entorno. 
educadora artística le realizaba. Eran preguntas sencillas y escuetas para que al/la participante no le resultara incómodo/a contestar. Las preguntas eran: ¿Qué has realizado? ¿Te ha gustado lo que has hecho? ¿Qué técnica has utilizado? Sí el educador comprobaba que era capaz de mantener un diálogo y una conversación fluida, la conversación se distendía en el tiempo; pero si se comprobaba que era difícil obtener respuesta, las preguntas se enfocaban a una respuesta con un sí o un no.

Los talleres se llevaron a cabo en una o dos sesiones que tenían una duración variable, entre 60 y 90 minutos. El número en las que participaron los usuarios giraba en torno a los 6 y 21 sesiones $(M=9.4, S D=5.4)$. Los motivos por los que las personas abandonaron el taller fueron por falta de afinidad con el resto del grupo.

A continuación, presentamos una serie de actividades implementadas en el proyecto, en las que se acerca la cultura a los participantes a través del Arte y la tecnología, como herramientas para entender conceptos analógicos y digitales mediante procesos de creación contemporáneos, con el objetivo de contribuir al disfrute, el juego y la experimentación, de manera que puedan desarrollar su propio proyecto de naturaleza artística y asociar conceptos de la cultura analógica con la digital. Asimismo en cada sesión trabajamos un área dentro del funcionamiento mnémico, la organización y la estimulación cognitiva (memoria a largo plazo y reminiscencia, lenguaje-afasia, orientación, atención, gnosis, funciones ejecutivas).

\section{Resultados.}

El análisis de resultados, y en concreto su evaluación, se llevó a cabo de manera consensuada entre los tres educadores que formaban el equipo, respondiendo a un formulario resumen (Cuadro 2) acerca de cada participante. El nivel de desacuerdo solía ser bajo y en caso de duda siempre se seleccionaba la opción de respuesta que menos compromiso implicaba (opción d) para la pregunta cuatro; opción b) o c) para la cinco; y opción c) para la seis.

En relación a la pregunta 4. ¿Ha manifestado interés y atención en el proceso del taller? de las 157 evaluaciones recogidas (Cuadro 2), hemos obtenido:

- El 59 por ciento (n-93) en la respuesta a. Sí, de forma continua durante toda la duración del mismo.
1. Fecha.

2. Identificación del taller.

3. Nombre del participante, género y nivel cultural.

4. ¿Ha manifestado interés y atención en el proceso del taller?

a) Sí, de forma continua durante toda la duración del mismo.

b) Sí, pero con intervalos.

c) No.

d) No se podría decir.

5. ¿Ha completado el trabajo del taller?

a) Sí.

b) A medias.

c) No.

6. ¿Ha disfrutado con la participación en el taller?

a) Sí, claramente, lo afirma o se observa sin ambigüedad.

b) Sí, posiblemente (es una deducción de los técnicos).

c) No podemos afirmar nada al respecto.

d) No ha disfrutado (se ha observado desagrado o disconformidad).

7. Observaciones sobre el participante.

8. Observaciones sobre el grupo.

Cuadro 2. Formulario resumen.

Fuente: Ullán et al., 2012.

- El 24 por ciento (n-37) en la respuesta b. Sí, pero con intervalos.

- El 17 por ciento (n-27) en la c. No, y por último en la d. No se podría decir, un 0 por ciento $(n-0)$.

Ante estos resultados, consideramos la participación, el esfuerzo y el interés mostrado por los participantes, factores clave en nuestro modelo educativo, siendo este de garantía, pues presentamos una valoración alta, el 83 por ciento, en su interés y atención durante el proceso del taller. Por el contrario, el porcentaje de participantes que consideramos que no han manifestado interés ni atención es poco relevante dentro del total de participantes analizados, estando este valor en torno al 17 por ciento. También destacamos un porcentaje nulo de participantes de los que no se podría precisar su interés y atención en el proceso del taller. 
En general la asistencia y participación en el taller ha sido muy positivas, el 90 por ciento (n7 de 8), pues en la mayoría de los casos todos querían estar en el taller, aunque en alguna ocasión fuera como meros espectadores, salvo en dos ocasiones que abandonaron el aula-taller dos participantes, uno por desavenencias con el grupo y el otro por estado de ansiedad y agitación previo al taller.

Respecto a la cuestión 5 ¿Ha completado el trabajo del taller?, hemos alcanzado en la respuesta a. Sí, el 33 por ciento(n-51). En la b. $A$ medias, el 64 por ciento(n-101) y en la c. No, el 3 por ciento(n-5). Si analizamos estas respuestas podemos afirmar que los participantes precisan más tiempo del estipulado para realizar la obra.

Seguidamente, contestando a la pregunta 6 . ¿Ha disfrutado del taller?, se obtuvieron los siguientes resultados, en la respuesta a. Sí claramente, lo afirma o se observa con ambigüedad, el 43 por ciento (n-49). En la respuesta b. Si, posiblemente (es una deducción de los técnicos) el 33 por ciento (n-37). En la c. No podemos afirmar nada al respecto, el 22 por ciento (n-25) y por último d. No se podría decir, el 8 por ciento (n-2).

En este punto tenemos que señalar que el 76 por ciento ha disfrutado en el taller, el ambiente generado en el mismo ha sido agradable y distendido. Frente al 8 por ciento que no podríamos especificar.

Por último en las preguntas 7. Observaciones sobre el participante y 8. Observaciones sobre el grupo, se han obtenido los siguientes puntos de vista de las personas afectadas-usuarios, representadas en los siguientes verbatim del tipo, «Pensé que nunca podría hacer algo así»; «Me gusta», «Pero... si lo he hecho yo», «Es mío, es mío - ¿Te gusta?».

Asimismo, cuidadores-familiares que acudían al taller de manera esporádica, el personal sociosanitario (n-1) y la trabajadora social (n-1) que intervenía al principio o al final del taller, que dependiendo del día y del turno que tuvieran, se iban rotando (Cuadro 3).

Finalmente, el carácter de esta investigación ha presentado una leve limitación, el tamaño de la muestra, que no nos permitió un análisis pormenorizado de los resultados en relación al diagnóstico neurológico y su repercusión con datos sociodemográficos. Asimismo, detectamos que para llevar un estudio más amplio de la incorporación del Arte como intervención en te-
1. «Este tipo de actividades les ayuda a comunicarse, conocerse, dialogar, me parece interesante».

2. «En general han mostrado interés, pero cada participante requiere de un trato individualizado y especial, debido al grado de demencia que presentan. También antes de finalizar el proceso se cansaban».

3. «La idea de que trabajemos varias con ellos les ayuda darles un trato individualizado y los usuarios que quisieron hacerlo lo hicieron, ninguno dijo no quiero, no me da la gana. ...Eso sí se necesita más tiempo para seguir...».

4. «Considero que este taller junto a los que hacen de música y danza, les hace sentirse capaces de seguir haciendo cosas y conocer cosas diferentes».

5. «Qué cosas tan bonitas hacen, eso les ayuda a sentirse bien».

Cuadro 3. Verbatim del personal sociosanitario y trabajadora social.

rapia no farmacológica, precisamos programaciones de educación artísticas dilatadas en tiempo y forma.

\section{Conclusiones}

Finalizado el estudio y análisis del programa de intervención creativa y psicosocial en arte y rducación, llevado a cabo con este perfil de participante, se comprobó que las sesiones tuvieron efectos positivos; no sólo respecto al estado de ánimo y autoestima del participante, repercutiendo directamente en su propio sentimiento de capacidad, sino también en el punto de vista el cuidador-familiar y personal socio-sanitario, pues percibe en su familiar la capacidad de tener interés, ser, estar y disfrutar del momento del taller. Las sesiones generaron una alta implicación de los usuarios, manifestada en la atención sostenida, la elevada participación y continuación en las sesiones, así como incluso en ocasiones el dominio de la técnica con el apoyo del educador artístico.

Durante el proceso del programa se percibieron conductas, lejos de la tristeza, agitación, ansiedad, agresividad y apatía, y estados muy presentes en la cotidianeidad de la convivencia con la enfermedad. En el caso de que esas conductas disruptivas estuvieran presentes antes de iniciar la sesión, estas disminuían progresivamente a medida que avanzaba la intervención. 
Asimismo, se pudieron observar expresiones y gestos de disfrute durante el proceso del taller, tanto en la fase de diálogo acerca de las obras de arte, como en la fase procesual, en la que se les daba indicaciones sobre los pasos que debían seguir para la realización de su propia obra, estas indicaciones y apoyos fomentaron la autonomía del usuario que en base a la repetición de procesos en cada sesión, en algunos casos generaba en ellos expresiones «Ya sé, ya sé yo... deja, deja, que yo puedo». También, el hecho de que una vez finalizada la obra objetual de la actividad, pudieran quedarse con ella, provocaba sentimientos de alegría por el detalle de que pudiera ser vista por sus familiares que no pueden visitarles.

Por lo tanto, consideramos importante que la actividad dé pie a la creación de productos u objetos artísticos, pues quedan impregnados de la sensación y vivencia del taller. Objetos que han permitido tanto a educadores como a personal sanitario, emplearlos como herramienta para establecer an- clajes y vínculos con la programación realizada; es decir, facilitó invitar a despertar recuerdos en él y la participante, una vez trascurrido el taller. El objeto ha supuesto ser una llave para hacer reminiscencia.

En conclusión, consideramos importantes y factibles los programas de intervención a través del arte, ya que es una herramienta muy apropiada y apta para ser empleada como intervención social, trabajando colaborativamente trabajadores sociales con artistas y educadores formados en este tipo de contextos, contribuimos a fomentar la inclusión de intervenciones de carácter multidisciplinar.

A pesar de las limitaciones que puede contraer la enfermedad en etapas iniciales, los usuarios pueden disfrutar de programas de educación artística, porque generan en ellos una mejor autopercepción y, por lo tanto, un estado de ánimo más positivo que, sin lugar a dudas, transforma la visión de la sociedad hacia este colectivo, desdibujando los mitos asociados a la enfermedad.

\section{Referencias bibliográficas}

Aidelman, N, y De Lucan, L. (2010). Jean-Luc Godard. Pensar entre imágenes: Conversaciones, entrevistas, presentaciones y otros fragmentos. Barcelona: Intermedio.

Calzado, Z., Ruiz M.I. y Espada, R. (2013). Arte y mayores: propuesta para un envejecimiento activo. Revista de Psicología, 2(1), 247-258.

Camic, P.M. Tischler, V. \& Pearman, C.H. (2014). Viewing and making art together: a multi-session artgallery- based intervention for people with dementia and their carers. Aging \& Mental Health. 1-8. doi: 10.1080/13607863.2013.818101.

Dewey, J. (1949). El Arte como experiencia. México D.F: Fondo de Cultura Económica.

Camic, P. \& Chatterjee, H. (2013). Museums and art galleries as partners for public health interventions. Perspectives. Public Health, 133(1), 66-71. http://dx.doi.org/10.1177/1757913912468523.

Chancellor, B., Duncan, A., \& Chatterjee, A. (2014). Art Therapy for Alzheimer's Disease and Other Dementias. Journal of Alzheimer Disease, 39, 1-11.

Eekelaar, C., Camic, P. \& Springham, N. (2012). Art Galleries, Episodic Memory and Verbal Fluency in Dementia: An Exploratory Study. Psychology of Aesthetics, Creativity, and the Arts. American Psychological Association, 6(3), 262-272. doi:10.1037/a0027499.

García Alba, J. y Melián Melián, J. (1993). Hacia un nuevo enfoque del trabajo social. Madrid: Narcea Ediciones.

Kinney, J.M. \& Rentz, C.A. (2005). Observed well-being among individuals with dementia: Memories in the Making, an art program, versus other structured activity. American Journal of Alzheimer's Disease and Other Dementias, 20, 220-227. doi: 10.1177 / 153331750502000406.

López, L. (2014). Educación Artística en personas con Demencia Temprana. International Journal of Developmental and Educational Psychology. INFAD. Revista de Psicología, 1(1), 527-534.

Marshall, M.J., \& Hutchinson, S.A. (2001). A critique of research on the use of activities with persons with Alzheimer's disease: A systematic literature review. Journal of Advanced Nursing, 35, 488-496. doi: 10.1046/j.1365-2648.2001.01887.x.

Molina, M. y Romero, M. (2004). Modelos de intervención asistencial, socioeducativo y terapéutico en trabajo social. San José: Editorial Universidad de Costa Rica.

Palmiero, M., Di Giacomo, D. \& Passafiume, D. (2012). Creativity and dementia: A review. Cognitive Processing, 1-17. 
Stuckey, H.L. \& Nobel J. (2010). The connection between art, healing, and public health: A review of current literature. Journal Public Health 100, 254-263. doi:10.2105/ AJPH.2008.156497.

Ullán, A.M. (2011). Una experiencia de educación artística contemporánea para personas con demencia. El Proyecto ARS: Arte y Salud. Arte, Individuo y Sociedad. 23. Número Extraordinario, 77- 88.

Ullán, A. et al. (2012). Contributions of an artistic educational program for older people with early dementia: An exploratory qualitative study. Dementia, $0(0)$. doi: 10.1177/ 1471301211430650.pp1-22.

Young, R., Camic, P.M. \& Tischler, V. (2015). The impact of community-based arts and health interventions on cognition in people with dementia: a systematic literature review. Aging \& Mental Health. 16, 1-15.

Zeisel, J. (2011). Todavía estoy aquí. Una nueva filosofía para el cuidado del alzheimer. Madrid: Edaf. 